\title{
Resim Arama Motorlarının Sorgu Sözcük Sayısına Göre Performans Değerlendirmeleri ${ }^{*}$
}

\author{
Performance Evaluation of Image Search Engines \\ Based on the Number of Query Words
}

\section{Erkan EMIRZADE $^{* \star}$ ve Yıltan BiTiRím ${ }^{* \star}$}

\begin{abstract}
Öz
Bu çalışmada, sorgu sözcük sayısının bilgi erişim etkinliği açısından resim arama motorları üzerindeki etkisi araştıılmıştır. Öncelikle, üç popüler resim arama motoru (Google, Yahoo ve MSN) seçilmiş ve Wordtracker'ın yayımlamış olduğu en sık aranan sorgular listesinden alınan 40 sorgu bir, iki, üç ve dört sözcüklü sorgu grupları şeklinde sınıflandırılmıştır. Seçilen sorgu sözcükleri resim arama motorlarında ayrı ayrı çalıştırılmış ve erişim çıktıları üzerinde ilgililik değerlendirmeleri yapılmıştır. Daha sonra arama motorlarının iki farkı kesme noktası (ilk 10 ve ilk 20) üzerinden farklı sorgu sözcük sayılarına göre erişim performansları duyarlılık ve normalize sıralama ölçütleri kullanılarak değerlendirilmiş ve genelde sorgu sözcük sayısı artık ça resim arama motorlarının bilgi erişim etkinliklerinde düşüş gözlenmiştir. Resim arama motorlarının geliştirilmesine ihtiyaç vardır.
\end{abstract}

Anahtar sözcükler: Resim arama motorları, Sorgu sözcük sayısı, Performans değerlendirme, Duyarlılık, Normalize sıralama.

\section{Abstract}

In this article, the impact of the number of query words on information retrieval effectiveness of image search engines was investigated. First of all, three popular search engines, namely, Google, Yahoo and MSN, were selected. Then, 40 queries were extracted from the list of Wordtracker

“Bu makale "Değişen Dünyada Bilgi Yönetimi Sempozyumu, 24-26 Ekim 2007, Ankara."da bildiri olarak sunulmuştur.

"Yakın Doğu Üniversitesi Bilgisayar Mühendisliği Bölümü, Lefkoşa, KKTC.

(erkan_emirzade@analiz-systems.com).

Doğu Akdeniz Üniversitesi Bilgisayar Mühendisliği Bölümü, Mağusa, KKTC.

(yiltan.bitirim@emu.edu.tr). 
and categorized in four groups as one-, two-, three- and four-word queries. After every query was run on the selected image search engines and binary human relevance judgments were done, the performance evaluation of image search engines was carried out on two cut-off points (first 10 and first 20 retrievals) in terms of precision and normalized recall. In general, the information retrieval effectiveness of image search engines decreases as the number of query words increases. Retrieval performance of image search engines needs to be improved.

Keywords: Image search engines, Number of query words, Performance evaluation, Precision, Normalized ranking.

\section{Giriş}

Bilgi çağında bilgiye hızı erişmek daha çok önem kazanmıştır. Genç olmasına karşın üzerinde barındırdığı bilgi yoğunluğuyla ve hızlı büyüyen yapısıyla Internet, insanların ilk başvuru kaynağı olmayı şimdiden başarmıştır. Yeni kayıt ortamı olan Internet hızlı gelişimini sürdürürken, bilgiye erişimde kullanılan arama motorları da kendilerini sürekli geliştirmeye devam etmektedir. Ne var ki arama motorlarının etkinliği artarken diğer taraftan düşük ilgililik ve büyük miktarlardaki veri sonuçları problem olmaya devam etmektedir (Zhang ve Mostafa, 2002). Bu nedenle yapılan birçok araştırma ve geliştirme çalışmasının amacı, bilgi erişim sistemlerinin etkinliğini ve verimliliğini artırarak kullanıcıların bilgi gereksinimlerinin daha iyi karşılanmasını sağlamaktır (Van Rijsbergen, 1979).

Internet büyüdükçe üzerinde saklanan resimler de artmaktadır (Fukumoto, 2006; Brilakis ve Soibelman, 2005). Bu artışla birlikte ilgili resimlere erişim daha karmaşık bir hal almıştır. Internet üzerinde ilgili resimlere erişim konularında birtakım çalışmalar (bkz. Stevenson ve Leung, 2005; Kuwabara ve Tanaka, 2005) yapılmış olmasına karşın, farklı sayıda sorgu sözcüğü kullanımının popüler resim arama motorları üzerindeki etkisi şimdiye kadar araştırılmamıştır.

$\mathrm{Bu}$ çalışmada, duyarlılık ve normalize sıralama ölçütleri kullanılarak farklı kesme noktaları (ilk 10 ve ilk 20) için sorgu sözcük sayısındaki değişimin seçilen popüler resim arama motorları (Google, Yahoo ve MSN) üzerindeki etkisi araştırılmıştır. 
Çalışmanın yöntem bölümünde deney için seçilen arama motorları, seçilen sorgu grupları, ilgililik değerlendirmeleri için kullanılan kıstaslar ve performans ölçümleri ele alınmıştır. Bulgular ve yorum bölümünde araştırmada elde edilen sonuçlar yorumlanarak verilmiş, sonuç kısmında ise elde edilen bulgular özetlenmiştir.

\section{Yöntem}

Artan sorgu sözcük sayısının resim arama motorları üzerindeki etkisini ölçmek için öncelikle üç popüler resim arama motoru seçilmiştir. Bunlar Google (www.google.com), Yahoo (www.yahoo.com) ve MSN'dir (www.msn.com). Daha sonra Wordtracker (http://www.wordtracker.com) tarafından Haziran 2006 tarihinde yayımlanmış en sık aranan sorgular listesinden kırk sorgu seçilmiştir. Wordtracker haftalık olarak güncellenen ve 330 milyonun üzerinde sorgu terimi içeren bir veri tabanını taramaktadır. Bu veri tabanındaki sorgu terimleri Dogpile ve Metacrawler gibi büyük meta-arama motorlarından toplanmaktadır. Gerekli deneyleri yapabilmek için farklı konulardan sorgular seçilmiş, bu sorgular bir, iki, üç ve dört sözcüklü olarak dört grupta sınıflandırılmıştır. Deneyde kullanılan sorgular ve grupları Tablo 1 'de verilmiştir.

Her sorgu seçilmiş resim arama motoru üzerinde tek tek ve bağımsız olarak çalıştırılmıştır. Araştırmamızda aynı sorgular farklı arama motorlarında mümkün olduğu kadar kısa aralıklarla çalıştırılmış ve bütün sorguların araştırıması yaklaşık bir haftada bitirilmiştir. Böylece sürekli çalışan dizinleme yazılımlarının iki arama motorunun denenmesi sırasında geçen zaman zarfında yeni adresleri dizinlemesi ve daha sonra denenen motorun bu nedenle daha başarılı bulunması olasılığı ortadan kaldırılmaya çalışılmıştır.

Internet kullanıcılarının \%80'i arama motoru sonuçlarının sadece ilk 20 öğesine (ilk iki sayfasına) bakmaktadır (Jansen ve Spink, 2003). Bu bilgiye dayanarak, erişilen ilk 20 resim "ilgili" ya da "ilgisiz" olarak değerlendirilmiş olup değerlendirme yazarlar tarafından ayrı ayrı yapılmış ve ilgililik kararı konsensüs yoluyla alınmıştır. İlgililik değerlendirilmesi yapılırken dikkat edilen noktalar 
(Bitirim, Tonta ve Sever, 2002) şunlardır: (1) Erişilen resim öğeleri teker teker incelenip "ilgili" veya "ilgisiz" olarak sınıflandırılmıştır; (2) aynı resmi içeren fakat farklı adresleri olan öğeler (mirror items), farklı resim öğeleri olarak değerlendirilmiştir; (3) aynı resmi içeren ve adresleri de aynı olan öğelerden ilki değerlendirilmiş, diğer(ler)i kullanıcının bakmayacağı düşünülerek "ilgisiz" kabul edilmiştir; ve (4) bağlantı olmasına rağmen bunların çalışmadığı durumlarda resim öğesi "ilgisiz" olarak kabul edilmiştir.

Duyarlılık ve normalize sıralama değerleri kesme noktası 10 ve kesme noktası 20 için teker teker hesaplanmıştır. Duyarlılık, sistem tarafından erişilen ilgili öğelerin erişim çıktısında yer alan (ilgili ve ilgisiz) toplam öğelere oranını verir. Duyarlılık değerleri 0 ile 1 arasında değişmektedir. Duyarlılık değerleri ne kadar yüksek olursa bir bilgi erişim sisteminin etkinliğinin de o kadar yüksek olduğu kabul edilmektedir (Vaughan, 2004). verilmiştir.

Duyarlıı̆ın $(D)$ hesaplanmasında kullanılan formül aşağıda

$$
\begin{gathered}
D=\text { Erişilen ilgili öğe sayısı / Erişilen } \\
\text { toplam öğe sayısı }
\end{gathered}
$$

Örneğin sorgu sözcüğü "araba" için sistemde 80 ilgili resim bulunmaktadır. Eğer "A" isimli resim arama motoru 60 adet resim öğesine erişiyorsa ve bunlardan 40 tanesi ilgili ise o zaman resim arama motorunun "araba" sorgu sözcüğü için duyarlılığı $40 / 60=0,67$ 'dir. Duyarlılık normalize sıralama ile yakından alâkalı bir ölçüttür (Yao, 1995). 
Tablo 1. Sorgu Listesi

\begin{tabular}{|l|l|l|l|l|l|l|l|}
\hline $\begin{array}{l}\text { S. } \\
\text { no }\end{array}$ & $\begin{array}{l}\text { Bir sözcüklü } \\
\text { sorgular }\end{array}$ & $\begin{array}{l}\text { S. } \\
\text { no }\end{array}$ & $\begin{array}{l}\text { İki sözcüklü } \\
\text { sorgular }\end{array}$ & $\begin{array}{l}\text { S. } \\
\text { no }\end{array}$ & $\begin{array}{l}\text { Üç sözcüklü } \\
\text { sorgular }\end{array}$ & $\begin{array}{l}\text { S. } \\
\text { no }\end{array}$ & $\begin{array}{l}\text { Dört sözcüklü } \\
\text { sorgular }\end{array}$ \\
\hline 1 & car & 11 & 50 cent & 21 & $\begin{array}{l}\text { valentine day } \\
\text { cards }\end{array}$ & 31 & $\begin{array}{l}\text { halloween } \\
\text { costumes for kids }\end{array}$ \\
\hline 2 & map & 12 & britney spears & 22 & white roller skate & 32 & $\begin{array}{l}\text { ray ban metal } \\
\text { sunglasses }\end{array}$ \\
\hline 3 & game & 13 & star wars & 23 & martin luther king & 33 & $\begin{array}{l}\text { calvin klein } \\
\text { deodorant perfume }\end{array}$ \\
\hline 4 & tattoo & 14 & crazy frog & 24 & $\begin{array}{l}\text { equipment travel } \\
\text { bag }\end{array}$ & 34 & $\begin{array}{l}\text { wood made musical } \\
\text { instruments }\end{array}$ \\
\hline 5 & flower & 15 & $\begin{array}{l}\text { halloween } \\
\text { costume }\end{array}$ & 25 & wild animal rescue & 35 & lord of the rings \\
\hline 6 & beach & 16 & funny picture & 26 & $\begin{array}{l}\text { wireless ethernet } \\
\text { bridge }\end{array}$ & 36 & $\begin{array}{l}\text { rosewood hand } \\
\text { made furniture }\end{array}$ \\
\hline 7 & simpsons & 17 & city map & 27 & $\begin{array}{l}\text { bottled drinking } \\
\text { water }\end{array}$ & 37 & $\begin{array}{l}\text { remote control } \\
\text { hobby toys }\end{array}$ \\
\hline 8 & amazon & 18 & hard job & 28 & antic wall clocks & 38 & $\begin{array}{l}\text { silver watch with } \\
\text { leather }\end{array}$ \\
\hline 9 & wallpaper & 19 & cat scan & 29 & $\begin{array}{l}\text { white sleeveless } \\
\text { shirt }\end{array}$ & 39 & $\begin{array}{l}\text { hydro electric } \\
\text { power plant }\end{array}$ \\
\hline 10 & cat & 20 & football shoes & 30 & pink rose bouquet & 40 & $\begin{array}{l}\text { pink high heeled } \\
\text { shoes }\end{array}$ \\
\hline
\end{tabular}

Normalize sıralama $\left(S_{\text {norm }}\right.$ ) erişilen öğelerden en ilgili olanın ilk sırada, ilgililik derecelerine göre diğer öğelerin de izleyen sıralarda yer alma başarımını ölçmeye yarayan bir ölçüttür. Normalize sıralama bilgi erişim sisteminin etkinliğini ölçmek için erişim çıktılarındaki sıralamayı kullanır (Yao, 1995). Normalize sıralama değerlerinin hesaplanması için kullanılan formül aşağıda verilmiştir.

$$
S_{\text {norm }}(\Delta)=\frac{1}{2}\left(1+\frac{S^{+}-S^{-}}{S^{+}{ }_{\max }}\right)
$$

$\Delta$ : Erişim çıktısı sıralaması;

$S^{+}$: Erişim çıktısında ilgili öğelerin ilgisiz öğelerin önünde yer aldığı öğe çiftleri sayısı;

$S$ : Erişim çıktısında ilgisiz öğelerin ilgili öğelerin önünde yer aldığı öğe çiftleri sayısı;

$S_{\text {max }}^{+}$: Mümkün olan en fazla $S^{+}$. 


\section{Bulgular ve Yorum}

Bu bölümde yapılan deneylerden elde edilen bulgular ve sonuçlar tartışılmıştır. Resim arama motorlarının performansları, erişilen ilgili öğe sayılarına göre değerlendirilebilir. Arama motoru üzerinde çalıştırılan her sorgu için erişilen ilk 20 resim "ilgili" ya da "ilgisiz" olarak değerlendirilmiştir. Bir, iki, üç ve dört sözcüklü sorgu grupları için erişilen ilgili resim öğe sayıları Tablo 2'de verilmiştir.

Tablo 2. Sorgu Grupları İçin Erişilen İlgili Resim Öğe Sayıları

\begin{tabular}{|c|c|c|c|c|c|c|c|c|c|c|c|c|c|c|c|}
\hline \multicolumn{4}{|c|}{$\begin{array}{l}\text { Bir sözcüklü sorgu } \\
\text { grubu }\end{array}$} & \multicolumn{4}{|c|}{$\begin{array}{l}\text { İki sözcüklü sorgu } \\
\text { grubu }\end{array}$} & \multicolumn{4}{|c|}{$\begin{array}{l}\text { Üç sözcüklü sorgu } \\
\text { grubu }\end{array}$} & \multicolumn{4}{|c|}{$\begin{array}{l}\text { Dört sözcüklü } \\
\text { sorgu grubu }\end{array}$} \\
\hline $\begin{array}{l}\stackrel{0}{c} \\
\text { ప్ర } \\
\text { के }\end{array}$ & 0 & $>$ & $\Sigma$ & $\begin{array}{l}\stackrel{\circ}{c} \\
\text { ప్ర } \\
\text { கे }\end{array}$ & 0 & $>$ & $\Sigma$ & 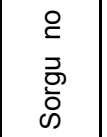 & (1) & $>$ & $\Sigma$ & 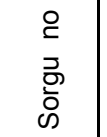 & (1) & $>$ & $\Sigma$ \\
\hline S1 & 13 & 17 & 14 & S11 & 19 & 19 & 20 & S21 & 20 & 13 & 15 & S31 & 14 & 4 & 11 \\
\hline $\mathrm{S} 2$ & 17 & 17 & 20 & $\mathrm{~S} 12$ & 20 & 20 & 20 & $\mathrm{~S} 22$ & 11 & 5 & 5 & S32 & 19 & 12 & 15 \\
\hline S3 & 17 & 4 & 9 & $\mathrm{~S} 13$ & 18 & 18 & 15 & $\mathrm{~S} 23$ & 15 & 18 & 15 & S33 & 16 & 16 & 20 \\
\hline $\mathrm{S} 4$ & 13 & 20 & 16 & S14 & 20 & 20 & 19 & S24 & 19 & 18 & 14 & S34 & 9 & 4 & 0 \\
\hline S5 & 16 & 19 & 17 & S15 & 15 & 15 & 9 & S25 & 5 & 2 & 3 & S35 & 13 & 17 & 9 \\
\hline S6 & 15 & 16 & 18 & $\mathrm{~S} 16$ & 10 & 11 & 8 & S26 & 17 & 17 & 15 & S36 & 11 & 19 & 0 \\
\hline S7 & 13 & 18 & 18 & S17 & 19 & 19 & 19 & S27 & 12 & 5 & 11 & S37 & 12 & 5 & 3 \\
\hline $\mathrm{S} 8$ & 4 & 3 & 3 & S18 & 7 & 5 & 3 & S28 & 20 & 14 & 14 & S38 & 17 & 13 & 19 \\
\hline S9 & 17 & 20 & 20 & S19 & 12 & 12 & 12 & S29 & 15 & 12 & 11 & S39 & 11 & 5 & 5 \\
\hline $\mathrm{S} 10$ & 18 & 19 & 19 & S20 & 17 & 17 & 8 & S30 & 19 & 16 & 15 & S40 & 13 & 1 & 6 \\
\hline Toplam & 143 & 153 & 154 & Toplam & 157 & 156 & 33 & Toplam & 153 & 120 & 118 & Toplam & 135 & 96 & 88 \\
\hline Ort. \% & 72 & 77 & 77 & Ort. \% & 78 & 78 & 67 & Ort. \% & 77 & 60 & 59 & Ort. \% & 68 & 48 & 44 \\
\hline
\end{tabular}

Not: G: Google; Y: Yahoo; M: MSN.

Bir sözcüklü sorgu grubundaki toplam 10 sorgu için Yahoo ve MSN sırasıyla 153 ve 154 ilgili resim öğesine erişirken, Google 143 ilgili öğeye erişmiştir (yaklaşık \%5 daha az). İki sözcüklü sorgu grubunda Google ve Yahoo sırasıyla 157 ve 156 ilgili öğeye erişmiş, MSN ise 133 ilgili öğeye erişmiştir (\%11 daha az). İki sözcüklü sorgu grubunda, bir sözcüklü sorgu grubuna göre artış gösteren Google, üç sözcüklü ve dört sözcüklü sorgu gruplarında kendi içinde düşüş yaşamıştır (sırasıyla 153 ve 135). Buna 
rağmen, üç sözcüklü ve dört sözcüklü sorgu gruplarında Google Yahoo'dan yaklaşık \%17 ve \%19, MSN'den de \%18 ve \%23 daha fazla ilgili resim öğesine erişmiştir. Başka bir deyişle, erişilen ilgili öğe sayısı açısından bakıldığı zaman sorgu sözcük sayısı artarken Google ile diğer arama motorları arasındaki fark da artmaktadır. Google bir sözcüklü sorgu grubu dışındaki tüm gruplarda en yüksek sayıda ilgili resim öğesine erişmiştir. Genel olarak tüm gruplar değerlendirildiğinde Google, Yahoo ve MSN sırasıyla yaklaşık olarak \%27, \%34 ve \%38 oranlarında ilgisiz resim öğesini erişim çıktılarında listelemişlerdir. Google ve Yahoo en iyi performanslarını iki sözcüklü sorgu grubunda elde etmişlerdir. MSN ise en iyi sonucu bir sözcüklü sorgu grubunda elde etmiş, fakat sorgu sözcük sayısı arttıkça erişebildiği ilgili öğe sayısı azalmıştır. MSN dört sözcüklü sorgu grubunda iki sorgu için ("wood made musical instruments" ve "rosewood hand made furniture") herhangi bir resim öğesine erişememiştir.

Google, Yahoo ve MSN resim arama motorlarının iki farklı kesme noktasındaki (ilk 10 ve ilk 20) ortalama duyarlılık oranları Şekil 1'de verilmektedir.

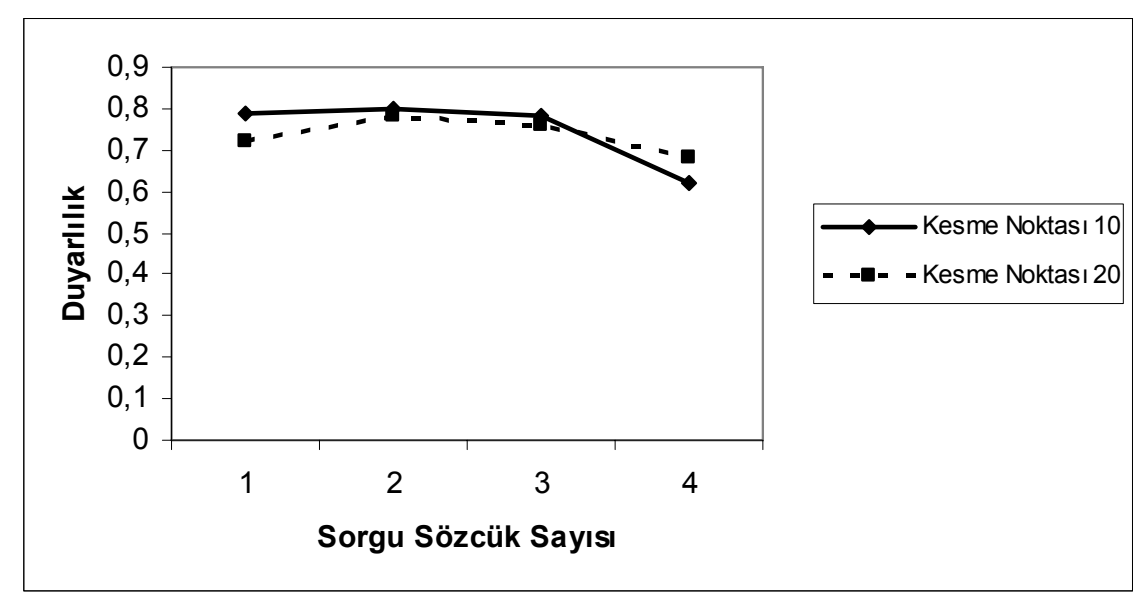

a) Google 


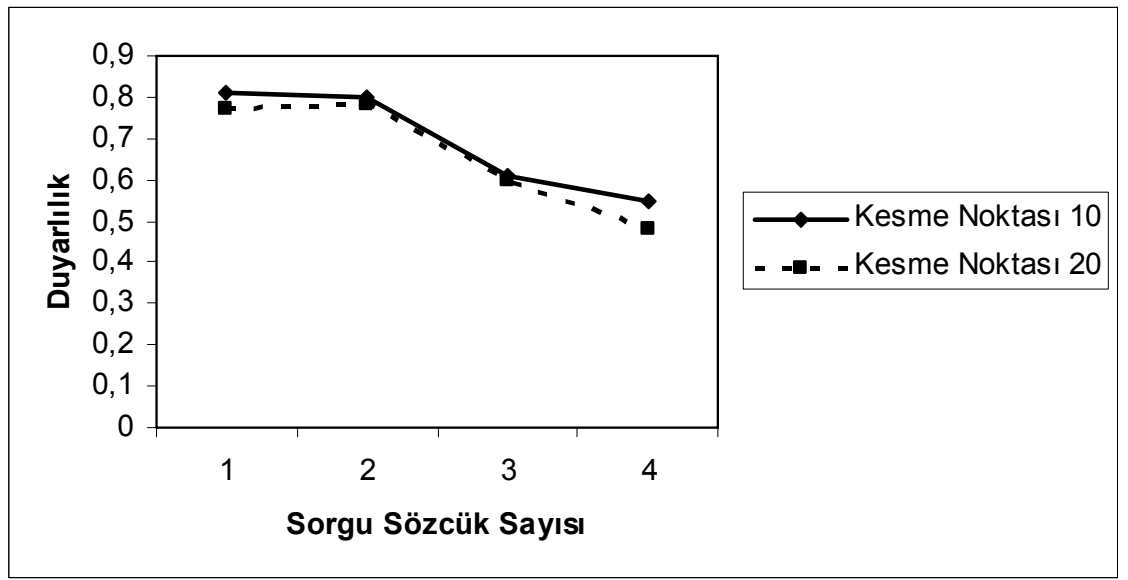

b) Yahoo

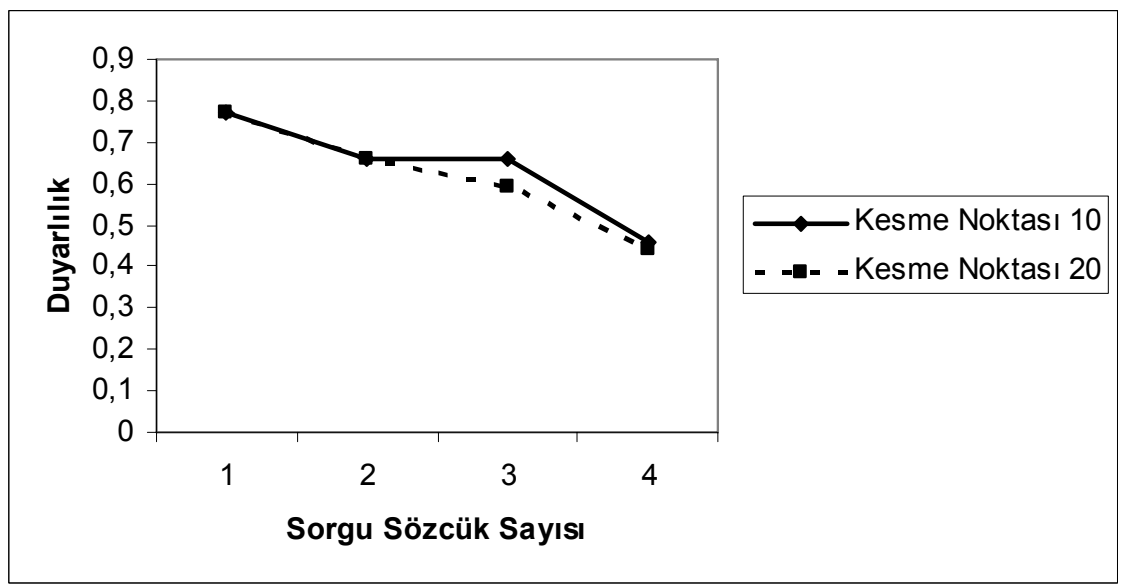

c) MSN

Şekil 1. Resim Arama Motorlarının Ortalama Duyarlııık Oranları:

a) Google; b) Yahoo; c) MSN

Google bir, iki ve üç sözcüklü sorgularda iki farklı kesme noktasında birbirine yakın ortalama duyarlılık performansı göstermiş, ancak dört sözcüklü sorgu grubunda ortalama duyarlılık oranı yaklaşık \%17 oranında düşmüştür (bkz. Şekil 1a). Kesme noktası 
20 'de sorgu sözcük sayısı birden ikiye çıktığında ortalama duyarlııı oranı \%6 artmıştır. Başka bir deyişle, Google'ın bir sözcüklü sorgu çıktılarında ilk 20 öğe arasında nispeten daha az ilgili öğe bulunmaktadır. Her iki kesme noktasında da Google resim arama motoru iki sözcüklü sorgularda en fazla ilgili öğeye erişirken, sorgu sözcük sayısı ikiden üçe çıktığında duyarlılık oranı biraz düşmüş, dört sözcüklü sorgu grubunda ise en düşük düzeye inmiştir.

Yahoo'nun kesme noktası 10'daki bir, iki, üç ve dört sözcüklü sorgular için ortalama duyarlılık oranları sırasıyla $\% 81, \% 80, \% 61$ ve \%55'tir (bkz. Şekil 1b). Yahoo'nun kesme noktası 20'deki performansı da benzer bir yönelim sergilemiş, üç ve dört sözcüklü sorgularda ortalama duyarlılık oranı sırasıyla \%17 ve \%29 düşmüştür. Açıkça görüldüğü gibi sorgu sözcük sayısı arttıkça ortalama duyarlılık oranları düşmektedir.

MSN resim arama motorunun her iki kesme noktasında da bir ve iki sözcüklü sorgular için ortalama duyarlılık performansı birbirine eşittir (bkz. Şekil 1c). Sorgu sözcük sayısı birden ikiye çıktığında ortalama duyarlııık oranı \%11 düşmüştür. Bu düşüş üç ve dört sözcüklü sorgularda da devam etmiş, dört sözcüklü sorgularda ortalama duyarlılık performansı \%50'nin altına düşmüştür. MSN'de de sorgu sözcük sayısı arttıkça ortalama duyarlılık oranları düşmüştür.

Genel olarak, sorgu sözcük sayısı arttıkça ortalama duyarlıık performansı her üç resim arama motorunda da düşmüştür. Bu düşüş Google'da nispeten daha azdır.

Google, Yahoo ve MSN resim arama motorlarının iki farklı kesme noktasındaki (ilk 10 ve ilk 20) ortalama normalize sıralama oranları Şekil 2'de verilmektedir.

Sorgu sözcük sayısı birden ikiye çıktığında Google'ın ortalama normalize sıralama oranları yaklaşık \%5'lik bir artış göstermiştir (bkz. Şekil 2a). 


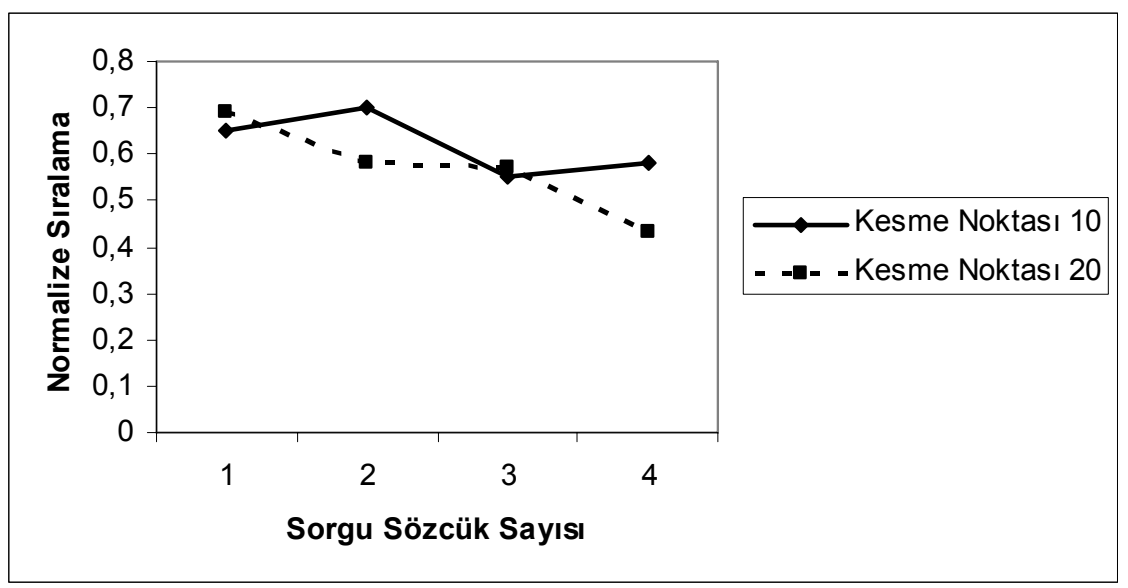

a) Google

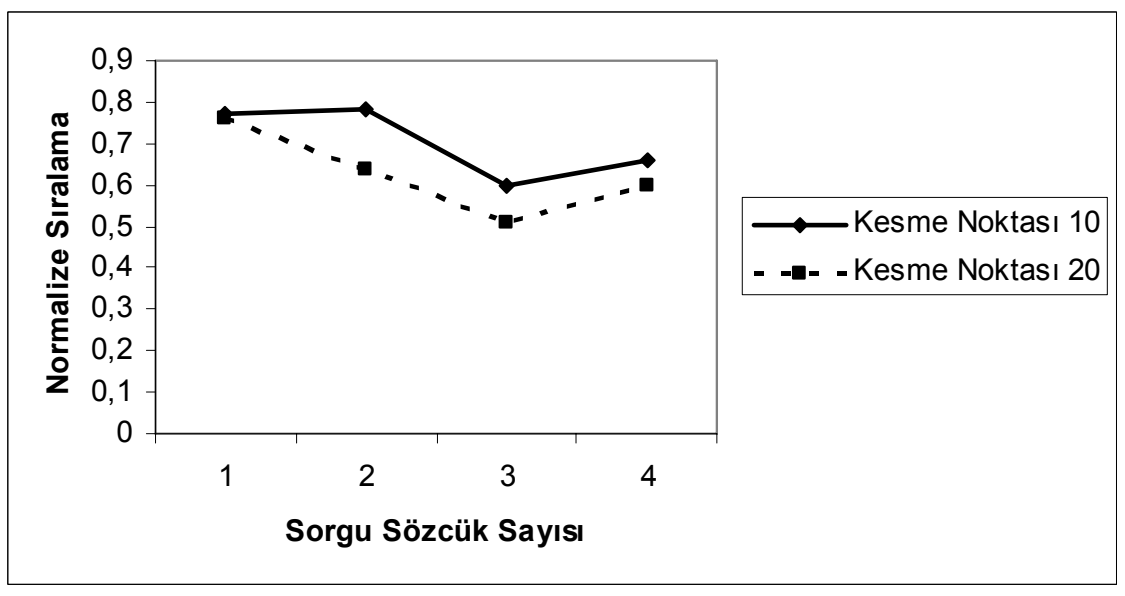

b) Yahoo 


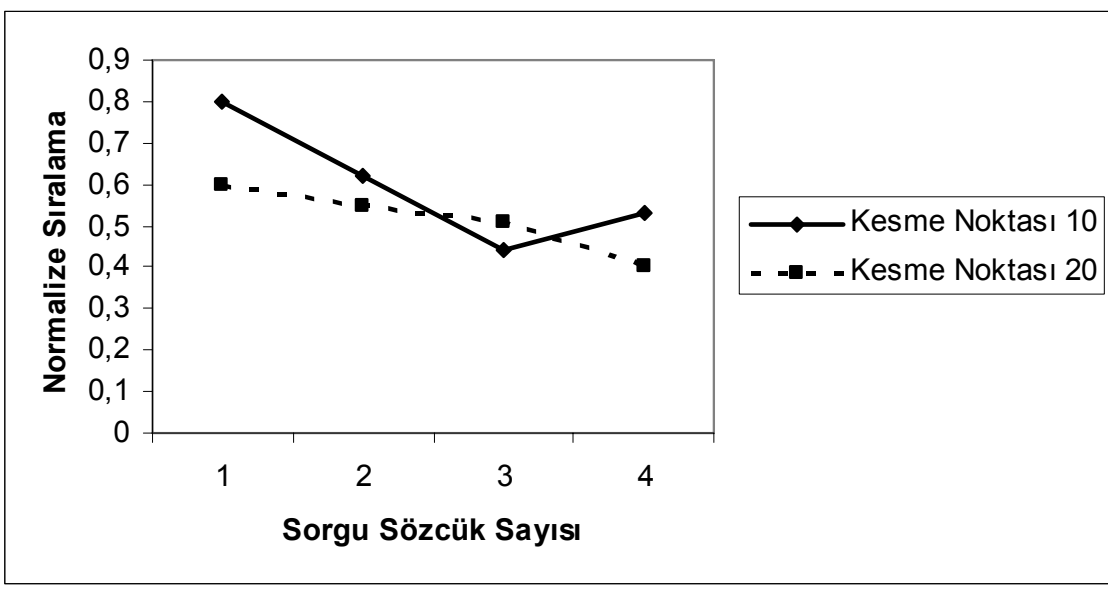

c) $\mathrm{MSN}$

Şekil 2. Resim Arama Motorlarının Ortalama Normalize Sıralama

Oranları: a) Google; b) Yahoo; c) MSN

Başka bir deyişle, iki sözcüklü sorgu sonuçlarında ilgili öğeler biraz daha üst sıralarda yer almıştır. Sözcük sayısı üç ve dörde çıktığında normalize sıralama performansı beklendiği gibi düşmüştür. Kesme noktası 20 'de ise sorgu sözcük sayısı artarken normalize sıralama oranlarında \%14'e kadar varan sürekli bir düşüş gözlenmiştir. Google'ın normalize sıralama oranları bir ve üç sözcüklü sorgular için kesme noktası 20'de kesme noktası 10'a göre yaklaşık $\% 4$ daha yüksektir. Öte yandan, Google iki ve dört sözcüklü sorgular için kesme noktası 10'da kesme noktası 20'ye göre sırasıyla \%12 ve $\% 15$ daha yüksektir. Google ilgili resim öğelerini ilk 10 sırada ilk 20'ye oranla daha üst sıralarda göstermektedir. Sorgu sözcük sayısı arttıkça ilgili öğeleri üst sıralarda gösterebilme başarısı da düşmektedir.

Yahoo'nun bir ve iki sözcüklü sorgulardaki ilk 10 resim öğesi için ortalama normalize sıralama oranları birbirine çok yakındır (bkz. Şekil 2b). Üç sözcüklü sorgularda bu oran düşmüş, dört sözcüklü sorgularda ise biraz $(\% 6)$ yükselmiştir. Bir, iki ve üç sözcüklü sorgularda ilk 20 resim öğesi için ortalama normalize sıralama oranları yaklaşık \%12'lik düşüşler göstermiş, dört 
sözcüklü sorgularda ise $\% 9$ oranında yükselmiştir. Sorgu sözcük sayısı artııça genelde Yahoo'nun ortalama normalize sıralama oranlarının düştüğünü söylemek mümkündür. Yahoo erişilen ilk 10 resim içinde ilgili olanları ilk 20'ye göre daha üst sıralarda göstermektedir.

MSN'de bir sözcüklü sorgular için kesme noktası 10 'da ortalama normalize sıralama oranı kesme noktası 20'ye göre \%20 daha yüksektir (bkz. Şekil 2c). Bu fark iki sözcüklü sorgularda $\% 7$ 'ye düşmüş, üç sözcüklü sorgularda ise kesme noktası 20'dekinden daha düşük düzeye (\%7) inmiş, dört sözcüklü sorgularda yeniden artmıştır (\%13). Google ve Yahoo'da olduğu gibi, MSN'de de sorgu sözcük sayısı arttıkça ilgili öğeleri üst sıralarda gösterebilme başarısı korunamamıştır. MSN de erişilen ilk 10 resim içinde ilgili olanları ilk 20'ye göre daha üst sıralarda göstermektedir.

\section{Sonuç ve Öneriler}

$\mathrm{Bu}$ çalışmada üç resim arama motorunun (Google, Yahoo ve MSN) iki kesme noktasında (ilk 10 ve ilk 20) farklı sorgu sözcük sayılarına göre erişim performansları duyarlılık ve normalize sıralama ölçütleri kullanılarak birinci dereceden istatistiksel olarak değerlendirilmiştir. Araştırmadan elde edilen sonuçlar şöyle özetlenebilir:

Google, Yahoo ve MSN resim arama motorlarında sorgularda yer alan sözcük sayısı arttıkça arama motorlarının duyarlılık performansları genelde düşmektedir. Duyarlılık oranları kesme noktası 10 iken genelde daha yüksektir. Başka bir deyişle, erişilen resim sayısı arttıkça duyarlılık oranları da düşmektedir.

Benzeri bir durum normalize sıralama oranları için de geçerlidir. Sorgu sözcük sayısı arttıkça arama motorlarının normalize sıralama performansları düşmektedir. Arama motorlarının kesme noktası 10'daki normalize sıralama oranları kesme noktası 20'dekilerden genelde daha yüksektir. Başka bir deyişle, erişilen resim sayısı arttıkça ilgili resimleri daha üst sıralarda gösterebilme başarısı düşmektedir. 
Her üç arama motoru için de sorgu sözcük sayısı üçten dörde çıktığında kesme noktası 10'da ortalama normalize sıralama oranlarının kısmi bir artış gösterdiği dikkati çekmektedir. Benzeri bir artış Yahoo için kesme noktası 20'de de söz konusudur. Sorgu sözcük sayısının daha da artmasının normalize sıralama oranlarında artış sağlayıp sağlamayacağı yanıtlanması gereken bir sorudur. İleriki çalışmamızda, sorgu sayısı artırılacak, kesme noktaları dörde $(5,10,15$ ve 20$)$ çıkarılacak ve değişik bilgi erişim sistemlerinin performansları arasında anlamlı derecede fark olup olmadığını test etmek için derinlemesine istatistiksel analizler yapılacaktır. Böylece, sorgu sözcük sayısı arttıkça resim arama motorlarının bilgi erişim performanslarının düşmesindeki etkenler daha ayrıntılı olarak incelenebilecektir.

Metin türü veri tabanlarında sorgu sözcük sayısı arttıkça bilgi erişim performansı artarken, resim içeren veri tabanlarında bunun tam tersi bir sonuç elde edilmesi dikkat çekicidir. Sorgu sözcük sayısı arttıkça Google, Yahoo ve MSN resim arama motorlarının ortalama duyarlılık ve ortalama normalize sıralama performansları düşmüştür. Bu sonuçlar resim arama motorlarının geliştirilmesi gerektiğini göstermektedir. Resim arama motorlarının bilgi erişim performansını artırmak için resimleri tanımlamada daha kapsamlı üst verilerin (metadata) ve resim ontolojilerinin kullanılması (image ontologies) ve örüntü tanıma algoritmaları ile makine öğreniminin geliştirilmesi gerekmektedir.

\section{Kaynakça}

Bitirim, Y., Tonta, Y. ve Sever, H. (2002). Information retrieval effectiveness of Turkish search engines. T. Yakhno (Ed.), Advances in Information Systems: Second International Conference, ADVIS 2002, İzmir, Turkey, October 23-25, 2002, Proceedings içinde (s. 93-103). Berlin: Springer-Verlag.

Brilakis, I., ve Soibelman, L. (2005). Content-based search engines for construction image databases. Automation in Construction, 14, 537-550. 
Fukumoto, T. (2006). An analysis of image retrieval behavior for metadata type image database. Information Processing \& Management, 42, 723-728.

Jansen, B.J. ve Spink, A. (2003). An analysis of web information retrieved and viewed. H.R. Arabnia ve Y. Mun (Ed.), Proceedings of the International Conference on Internet Computing, IC '03, Las Vegas, Nevada, June 23-26, 2003 (2 vols.) içinde (s. 65-69). Las Vegas: CSREA. 21 Temmuz 2007 tarihinde http://www.viktoria.se/ dixi/BISON/resources/ jansenspink-2003.pdf adresinden erişildi.

Kuwabara, A. ve Tanaka, K. (2005). RelaxImage: A cross-media metasearch engine for searching images from web based on query relaxation. Proceedings of the 21st International Conference on Data Engineering, ICDE 2005, April 5-8, 2005, Tokyo, Japan içinde (s. 1102-1103). Tokyo: IEEE Computer Society.

Stevenson, K. ve Leung, C. (2005). Comparative evaluation of web image search engines for multimedia applications. H.Ip.A. Smeaton, J. Smith ve A.W.M. Smeulders (Ed.), Proceedings of the International Conference on Multimedia and Expo, July 6-8, 2005, Amsterdam, The Netherlands içinde (s. 4). Amsterdam: IEEE Press.

Van Rijsbergen, C.J. (1979). Information retrieval (2nd ed.). London: Butterworths.

Vaughan, L. (2004). New measurements for search engine evaluation proposed and tested. Information Processing \& Management, 40, 677-691.

Yao, Y.Y. (1995). Measuring retrieval effectiveness based on user preference of documents. Journal of the American Society for Information Science, 46, 133-145.

Zhang, J. ve Mostafa, J. (2002). Examining the relationships among user involvement, profile quality, and information filtering performance. Proceedings of the American Society for Information Science and Technology Annual Meeting, 39, 298306. 